Cómo citar esta reseña: Villegas Vélez, A. A. (2018). Reseña del libro Residuos de la violencia. Producción cultural colombiana, 1990-2010, de A. Fanta Castro. Estudios de Literatura Colombiana 42, pp. 211-214. DOI: https://doi.org/10.17533/udea.elc.n42a14

1 aavilleg@unal.edu.co

Universidad Nacional de Colombia, Sede Medellín

Recibido: 15.08 .2017

Aprobado: 11.11.2017
Copyright: $\odot 2018$ EstudiosdeLiteratura Colombiana. Este es un artículo de acceso abierto distribuido bajo los términos de la Licencia Creative Commons AtribuciónNo comercial-Compartir igual 4.0 Internacional

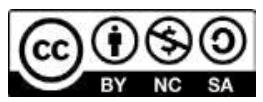

\section{RESIDUOS DE LA VIOLENCIA. ProduCCIÓN CULTURAL COLOMBIANA, 1990-2010 Andrea Fanta Castro*}

\author{
EDITORIAL UNIVERSIDAD DEL RoSARIO, \\ Bogotá, 2013, 164 P.
}

Álvaro Andrés Villegas Vélez ${ }^{1}$

Residuos de la violencia. Producción cultural colombiana, 1990-2010 hace parte de un conjunto de libros y artículos publicados en la última década y realizados por investigadores formados que en gran medida desarrollan su carrera profesional en los departamentos de español o lenguas romances de las universidades estadounidenses. $\mathrm{Si}$ bien este corpus es diverso, existen algunos rasgos relativamente compartidos que podríamos sintetizar de la siguiente manera: 1) énfasis en las narraciones y obras sobre las violencias, es decir, sobre el complejo y multiforme conflicto armado de las últimas tres décadas entre fuerzas estatales, paraestatales, guerrilleras y grupos asociados al narcotráfico; 2) el análisis de estas producciones culturales desde referentes teóricos europeos, sobre todo desde la denominada French Theory: Michel Foucault, Jacques Derrida, Gilles Deleuze, Jacques Lacan, Julia Kristeva, a lo que se suman autores contemporáneos también franceses como Jean-Luc Nancy, Jacques Rancière y Georges Didi-Huberman, filósofos políticos italianos como Giorgio Agamben, Maurizio Lazzarato y Roberto Esposito, críticos culturales ya fallecidos como Walter Benjamin o activos actualmente como Slavoj Žižek, y autoras feministas o poscoloniales como Judith Butler y Gayatri Chakravorty Spivak; 3) el interés por vincular las obras analizadas, desde las perspectivas teóricas anteriormente mencionadas, a problemas 
que exceden lo estrictamente literario como las diferencias y desigualdades de género y de etnia, la memoria de los grupos subalternos y la violencia contra estos, 4) finalmente el esfuerzo por ampliar el canon, al incluir dentro del análisis literaturas menores producidas por grupos subalternos, tanto desde géneros más tradicionales como la novela, el cuento y la poesía, pero también en registros de carácter testimonial; a la par que el análisis de estas obras escritas se combina, en ocasiones, con la preocupación por las artes visuales, el cine y el cómic, lo que ha llevado al uso del término "producción cultural" para designar los heteróclitos corpus analizados.

En el caso concreto del libro aquí reseñado, el foco apunta, como su título lo hace explícito, a los residuos de la violencia, más exactamente a los cuerpos que la acción de las violencias transforma en restos humanos dentro de una sociedad neoliberal que produce, distribuye, consume y desecha sin cesar objetos y seres. A juicio de Fanta Castro, los cuerpos residuales y, por ende, condenados a la marginalidad por la sociedad, la economía y la política colombiana son situados en el centro de una serie de producciones culturales colombianas de los últimos 30 años. Al respecto, la autora plantea:

Este libro piensa entonces a Colombia desde su cultura, su historia e intenta devolver una posibilidad, otra, para leer (su siempre cambiante) realidad. Todas las representaciones que aquí se analizan no solamente señalan un Estado obsoleto, un sistema judicial ineficiente, una carencia de instituciones sociales y políticas inclusivas, y el impacto penetrante de la economía de mercado, también señalan una serie de prácticas y de instituciones paralelas que sustituyen a las oficiales. En este contexto particular, gobernado más por la excepción que por la regla, emergen los cuerpos residuales (p. XXVII).

Estos habitan un presente absoluto, despojado de una continuidad que los vincule al pasado y al futuro y, por ende, a la historia y a la sociedad, de una forma que recuerda la que puede ser una de las obras pioneras de esta tendencia, Rodrigo D: no futuro, cuyos personajes habitan la pura intensidad del presente bajo la premisa de "será muerte vivir tanto". En este sentido, el sicario se vuelve la figura paradigmática de este tipo de cuerpos, por lo cual la autora analiza las novelas Rosario Tijeras y La virgen de los sicarios, así como sus respectivas adaptaciones cinematográficas, para luego pasar a dos novelas de Mario Mendoza, Satanás y Scorpio City. Todas estas narraciones plantean un exceso: de cuerpos, de violencia, de drama, de acumulación; un exceso que el Estado no logra integrar bajo la forma ciudadano, pero que el capitalismo neoliberal consigue refuncionalizar bajo la forma mercancía.

A la par del cuerpo como exceso, aun en su carácter residual, este también puede conformarse como una ausencia o, mejor, como la presencia 
de una ausencia, y, en este sentido, como un espectro que hace evidente que ninguno de estos estados son plenos. En la historia colombiana reciente, dicho carácter espectral está condensado en las víctimas de desaparición forzosa y en los cuerpos (sin vida) no identificados. Las producciones culturales recientes han hecho de esta espectralidad su objeto de interés, como lo muestran la novela Perder es cuestión de método de Santiago Gamboa y las obras Atrabiliarios y Unland de la artista visual Doris Salcedo, quienes realizan su trabajo estético y crítico a partir de la espectralidad, la cual no pretenden colmar sino hacer evidente en su carácter fantasmático.

Finalmente, la autora se concentra en tres obras de carácter literario: Vida feliz de un joven llamado Esteban, El olvido que seremos y Todo pasa pronto, las cuales recuperan los relatos de los vencidos a partir de un yo que vemos emerger desde la infancia - no en vano las tres novelas tienen algo de Bildungsroman sin serlo completamente- . Todas expresan, además, el desplazamiento de unas narraciones más concentradas en la explicación estructural de la Historia al acercamiento a la Historia desde lo micro, desde las historias de personajes que la viven y la sufren, pero distan de ser sujetos capaces de transformarla.

El recorrido que le plantea al lector Fanta Castro está marcado por obras que en su especificidad y diversidad intentan, a veces de forma contradictoria y limitada, tomar una posición frente a los residuos que produce la violencia neoliberal, caracterizada por el abandono del Estado y la preeminencia del capitalismo salvaje. A esa producción de cuerpos residuales se enfrentan, con sus limitaciones, las obras analizadas, las cuales buscan dotar, más que de voz, de tiempo a estos cuerpos desechados para evitar su desaparición completa. Se trata, pues, de hacerlos parte de lo que investigadores alemanes como Aleida y Jan Assmann y Ute Seydel han denominado memoria cultural, entendida como aquella que es exteriorizada y objetivada en artefactos de diverso tipo que pueden difundir sus contenidos a distancia. Tal vez sea esta la razón por la cual la autora se limita a obras literarias publicadas por las grandes editoriales, a películas exitosas en taquilla o a obras como las de Doris Salcedo expuestas en instituciones artísticas consagradas y consagrantes, lo cual incrementa su visibilidad y su posibilidad de pervivencia; no obstante, y a pesar del derecho de cada investigador en escoger el conjunto de obras que analizará, seguramente el contraste de este corpus con obras menos visibles, si se quiere marginales, podría haber ayudado a desvelar otras facetas de los residuos de las violencias en la producción cultural colombiana. También 
pareciera, por momentos, que las discusiones teóricas fueran un fin en sí mismas, desplazando la interpretación teórica de las narrativas y objetos artísticos. No obstante, estas objeciones no son óbice para recomendar este libro, el cual viene a nutrir la comprensión de nuestras violencias y de las producciones culturales que las tratan. 